\title{
MOLECULAR INTERACTION OF CURCUMIN, DEMETHOXYCURCUMIN, BISDEMETHOXYCURCUMIN, AND TURMERONE OF Curcuma longa WITH TYROSINASE AND TYROSINASE-RELATED PROTEIN-1
}

\author{
D. Firmansyah, ${ }^{1,2}$ S. A. Sumiwi, ${ }^{2}$ N. M. Saptarini ${ }^{3}$ and J. Levita ${ }^{2, 凶}$ \\ ${ }^{1}$ Department of Pharmacology, School of Pharmacy Muhammadiyah Cirebon, \\ Cirebon-45153, (West Java) Indonesia \\ ${ }^{2}$ Department of Pharmacology and Clinical Pharmacy, Universitas Padjadjaran, \\ Sumedang-45363, (West Java) Indonesia \\ ${ }^{3}$ Department of Pharmaceutical Analysis and Medicinal Chemistry, Universitas Padjadjaran, \\ Sumedang-45363, (West Java) Indonesia \\ ${ }^{\bowtie}$ Corresponding author: jutti.levita@unpad.ac.id
}

\begin{abstract}
Melanogenesis, which takes place in the melanosome, is enhanced by the activation of tyrosinase and tyrosinaserelated protein. Tyrosinase has an inner melanosomal domain that contains the catalytic region and is connected to a short transmembrane domain and a cytoplasmic domain. Histidine residues are present in the catalytic site of tyrosinase and bind the copper ions that are required for tyrosinase activity. Tyrosinase-related proteins, which are similar to tyrosinase, activate and stabilize this enzyme. Phytoconstituents, e.g., curcumin, have been proven could block the melanogenesis process in human melanocytes. It is interesting to study the molecular interaction of curcumin, demethoxycurcumin, bisdemethoxycurcumin, and turmerone of Curcuma longa with tyrosinase and TRP1 by molecular docking simulation. The results indicate that all ligands could bind to tyrosinase and TRP-1, and interestingly, their binding modes are similar to those of kojic acid. Of all ligands, turmerone binds strongly to tyrosinase, whereas bisdemethoxycurcumin shows the strongest affinity to TRP-1. Considering this, Curcuma longa could be further developed as a plant-based skin whitening-cosmetic.
\end{abstract}

Keywords: Curcumin, Curcuma longa, Tyrosinase, Tyrosinase-related Protein

RASĀYAN J. Chem., Vol. 14, No.4, 2021

\section{INTRODUCTION}

Melanogenesis, which takes place in the melanosomes, is enhanced by the activation of tyrosinase and tyrosinase-related protein (TRP). Tyrosinase has an inner melanosomal domain that contains the catalytic region and is connected to a short transmembrane domain and a cytoplasmic domain. Histidine residues are present in the catalytic site of tyrosinase and bind the copper ions that are required for tyrosinase activity. This enzyme catalyzes the hydroxylation of L-tyrosine to L-dihydroxyphenylalanine (L-DOPA), the successive oxidation reaction producing the L-dopaquinone, and 5,6-dihydroxyindole to 5,6indolequinone. ${ }^{1,2}$ Tyrosinase-related protein-1 (TRP-1), which is also present in the membrane of melanosomes, activates and stabilizes the tyrosinase, as well as fights against oxidative stress due to its peroxidase effect. ${ }^{3}$ The term tyrosinase refers to its typical substrate, tyrosine, ${ }^{2}$ therefore, by competitively inhibiting the binding of this substrate to the enzyme, the production of melanin could be prevented.

The melanogenesis process was reported could be inhibited by ethyl p-methoxycinnamate (EPMC), galangin, 6-gingerol, 4-hydroxypanduratin-A, isopanduratin-A, kaempferol, and kaempferide, the phytoconstituents of Zingiberaceae plants. ${ }^{2,4,6}$ Galangin and kaempferol, two flavonols contained in Heterotheca inuloides, inhibit the enzyme by chelating the copper in the catalytic pocket, due to their free 3-hydroxyl group. ${ }^{5}$ Kaempferide and galangin inhibited mRNA expression of tyrosinase and TRP-1 and 2 , and the protein level of a microphthalmia-associated transcription factor (MITF) ${ }^{6}$ Furthermore, plant- 
polyphenol, e.g. curcumin, inhibits melanogenesis in human melanocytes via the activation of Akt/GSK $3 \beta$, ERK, or p38 MAPK signaling pathways. ${ }^{7}$

However, it is interesting to study the molecular interaction of curcumin, demethoxycurcumin, bisdemethoxycurcumin, and turmerone of Curcuma longa with tyrosinase and TRP-1.

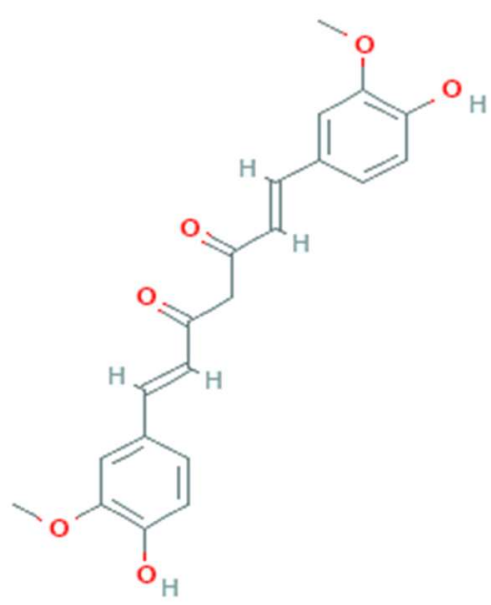

(1)

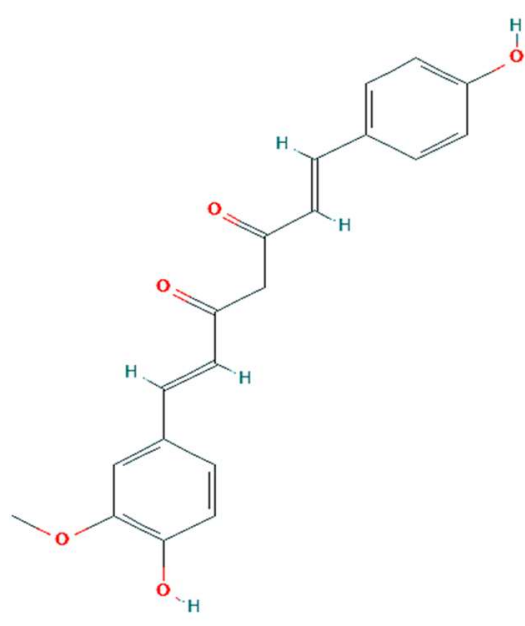

(2)

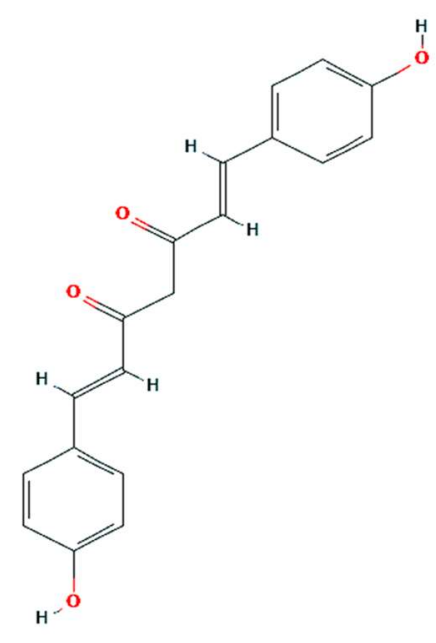

(3)

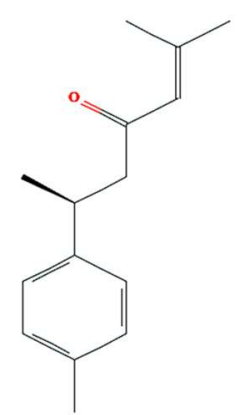

(4)

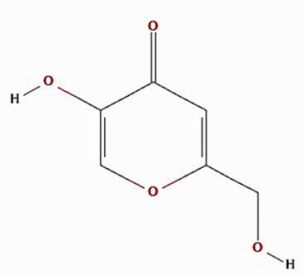

(5)

Fig.-1: 2D Molecular Structure of (1) Curcumin, (2) Demethoxycurcumin, (3) Bisdemethoxycurcumin, and (4) Turmerone of Curcuma longa. Kojic Acid (5) is Used as the Standard. Structures of Ligand were Built Using

ChemDraw Professional 15.0.

\section{Hardware and Software}

\section{EXPERIMENTAL}

The hardware used was Acer Swift 3 SF313-51 (mid-2019) embedded with Windows 10 home edition, 1,60 GHz quad-core Intel Core i5-8130U processor, 8GB $2133 \mathrm{MHz}$ DDR4, and Intel UHD Graphics 620. Software used was SwissPdbV v. 4.1.0, ChemDraw Professional 15.0, Chem3D 15.0, AutoDock 1.5.6, and Discovery Studio Visualizer (Freeware).

\section{Preparation of Ligands and Molecular Docking}

The 2D structure of all test ligands was built using ChemDraw Professional 15.0. The ligands were subsequently converted to a 3D structure and then subjected to energy minimization using the MMFF94 forcefield partial charges.

The x-ray crystallographic 3D structure of Bacillus megaterium tyrosinase (PDB ID 3NQ1) crystallized and deposited by Sendovski et al., (2010) resolution $2.3 \AA$ was downloaded from online Protein Data Bank (https://www.rcsb.org/structure/3NQ1). Tyrosinase is a homodimer enzyme in the asymmetric unit. Two copper (II) ions, the major cofactors within the active site, are coordinated by six conserved histidine residues. ${ }^{8}$ The monomer was separated and repaired using Swiss-PdbViewer. Kojic acid that was cocrystallized in the enzyme was extracted and saved to be used for validation. 
The x-ray crystallographic 3D structures of human TRP-1 (PDB ID 5M8M) crystallized and deposited by Lai et al., (2016) resolution $2.65 \AA$ was downloaded from the online Protein Data Bank (https://www.rcsb.org/structure/5M8M). The typical tyrosinase-like subdomain of TYRP-1 contains two zinc ions in the active site. In addition, the cysteine-rich subdomain has an epidermal growth factor-like fold and is tightly associated with the tyrosinase subdomain. ${ }^{9}$ The monomer was separated and repaired using Swiss-PdbViewer. Kojic acid that was co-crystallized in the enzyme was removed.

Molecular docking was carried out for all the test compounds into the catalytic pocket of tyrosinase and the binding site of human TRP-1 by employing AutoDock. The flexibility of tyrosinase and human TRP-1 was regulated by setting the scaling factor for the nonpolar atoms to 0.8 . All other parameters were fixed at the default condition. At the end of docking, the structures were ranked by energy, as were the clusters, and binding free energy of each run was provided in the docking log (dlg) file. The binding affinity of the receptor/ligand complexes was expressed in terms of docking scores. ${ }^{10,11}$

\section{RESULTS AND DISCUSSION}

Two copper (II) ions, serving as the major cofactors in the catalytic site of tyrosinase, are covalently bound by six conserved histidine residues (His42, His60, His69, His204, His208, and His231) in the catalytic pocket of tyrosinase as depicted in Fig.-2. The catalytic site of tyrosinase (PDB ID 3NQ1) lies at coordinates: $\mathrm{x}=-8.689, \mathrm{y}=-19.433, \mathrm{z}=6.600$. The dimension of the grid box are $\mathrm{x}=20$ points, $\mathrm{y}=16$ points, $\mathrm{z}=40$ points, spacing $0.375 \AA$, centered on important amino acid residues.

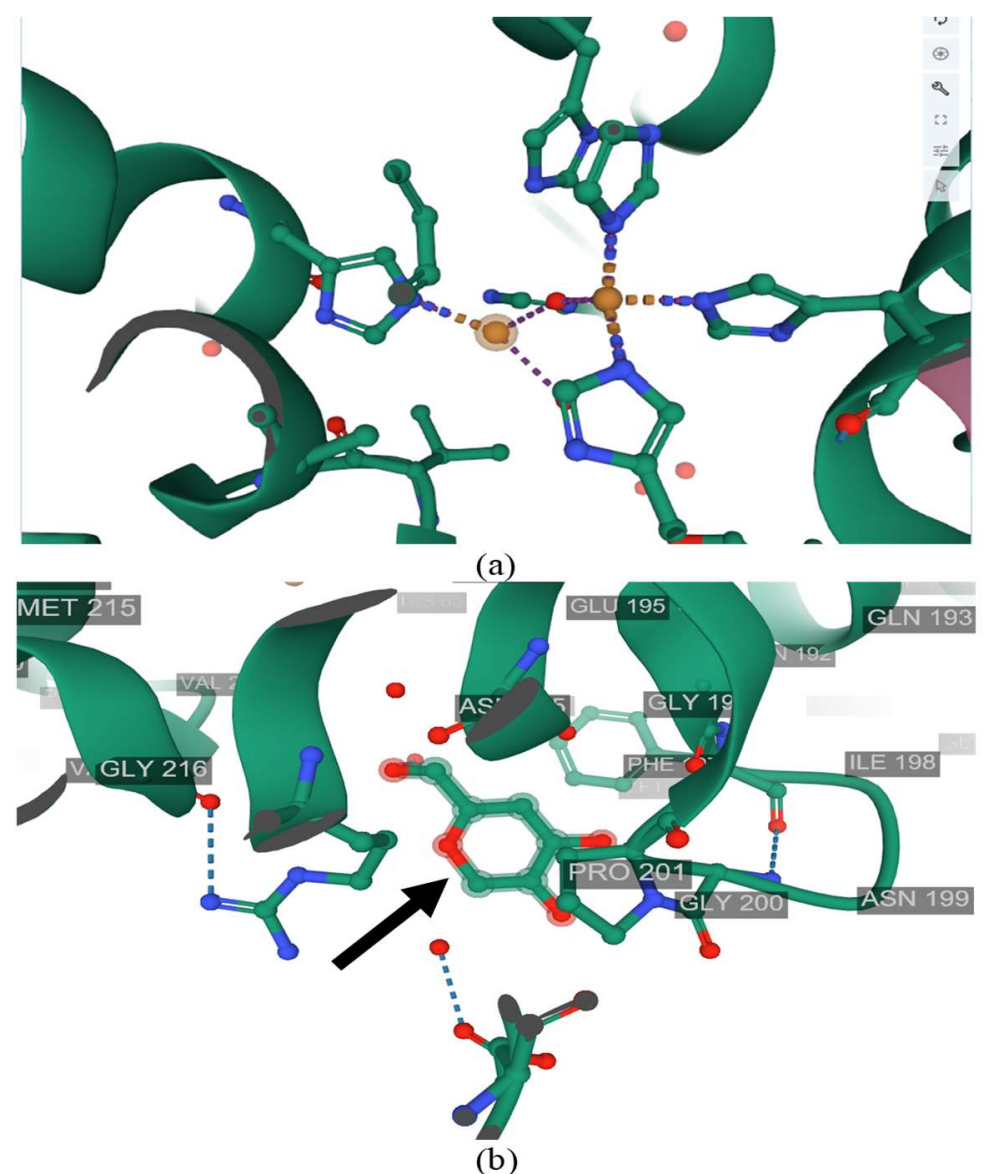

Fig.-2: (a) The Catalytic Site of Tyrosinase (PDB ID 3NQ1) Contains Two Copper Ions (shown as brown balls) Surrounded and Coordinated by Six Histidine Residues; (b) Kojic Acid in the Catalytic Site of Tyrosinase (shown by black bold arrow).

The re-docking of kojic acid into its origin location reveals that this compound interacts with critical amino residues by building hydrogen bonds and pi-alkyl interactions with Pro201 and Arg209 (Fig.-3). This particular hydrophobic contact with Pro201 corresponds to that of Sendovski et al. (2007). ${ }^{8}$ 


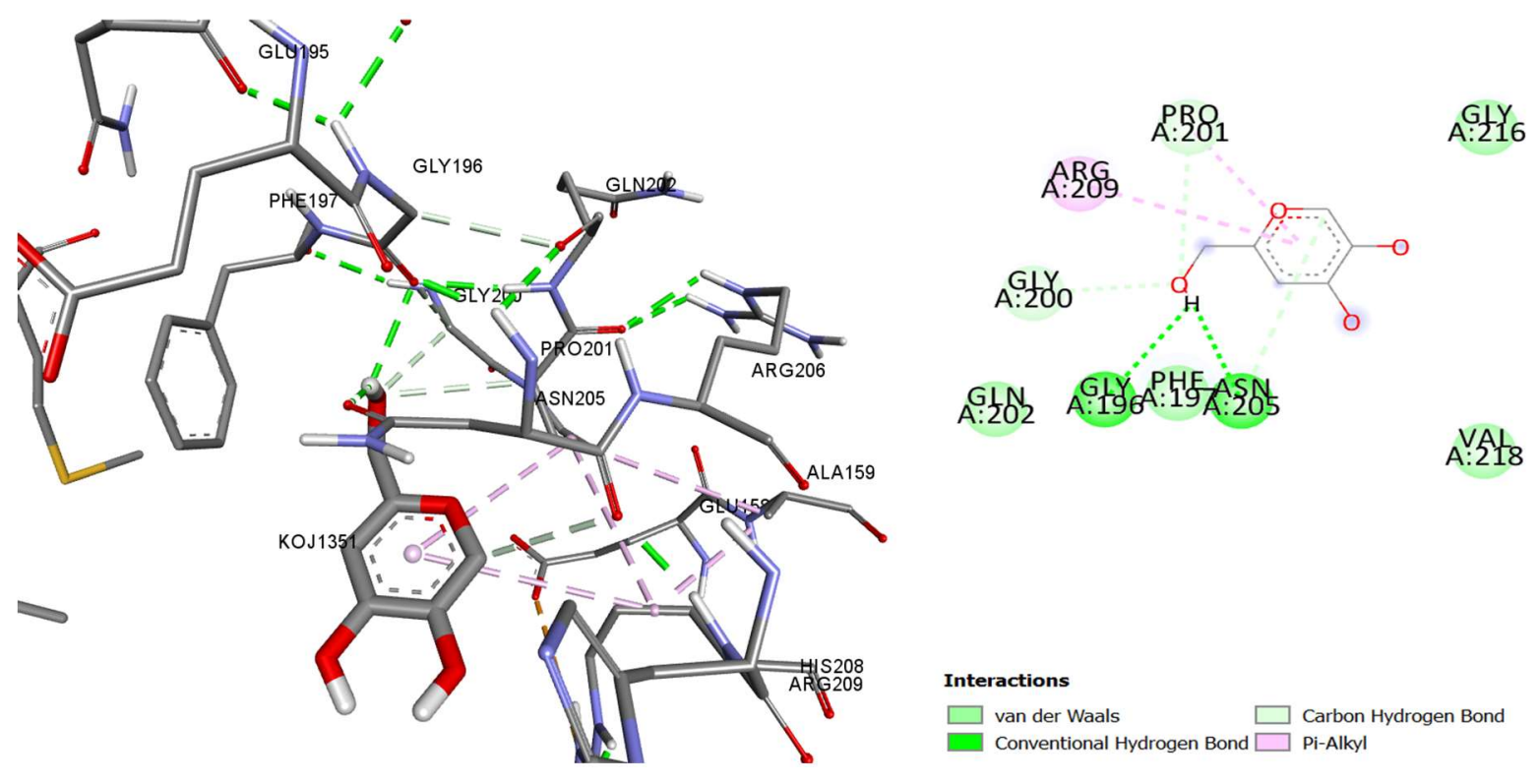

Fig.-3: Re-docking of Kojic Acid to Its Origin Position Reveals Two Hydrogen Bonds (green dashed-lines) with Asn205 and Gly196 and Pi-Alkyl Interaction (pink dashed-lines) with Pro201 and Arg209.

Kojic acid, chemical name 5-hydroxy-2-hydroxymethyl-4H-pyran-4-one, has been widely used as a ultraviolet protector, skin lightener, suppressor of hyperpigmentation in humans and blocker of melanin formation due to its tyrosinase inhibitory activity. ${ }^{12}$ This compound could inhibit both the cresolase and catecholase activity of mushroom tyrosinase. ${ }^{11}$

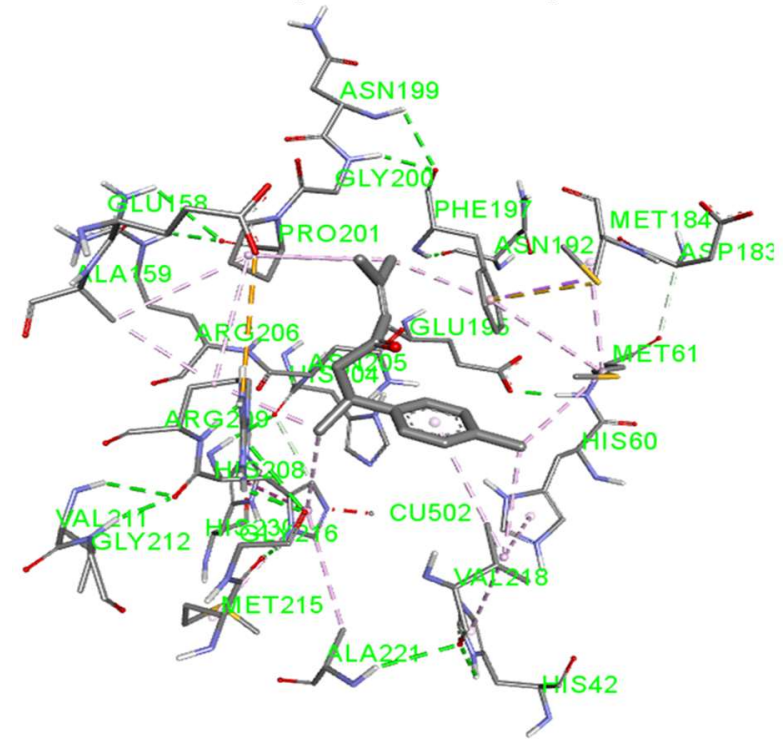

(a)

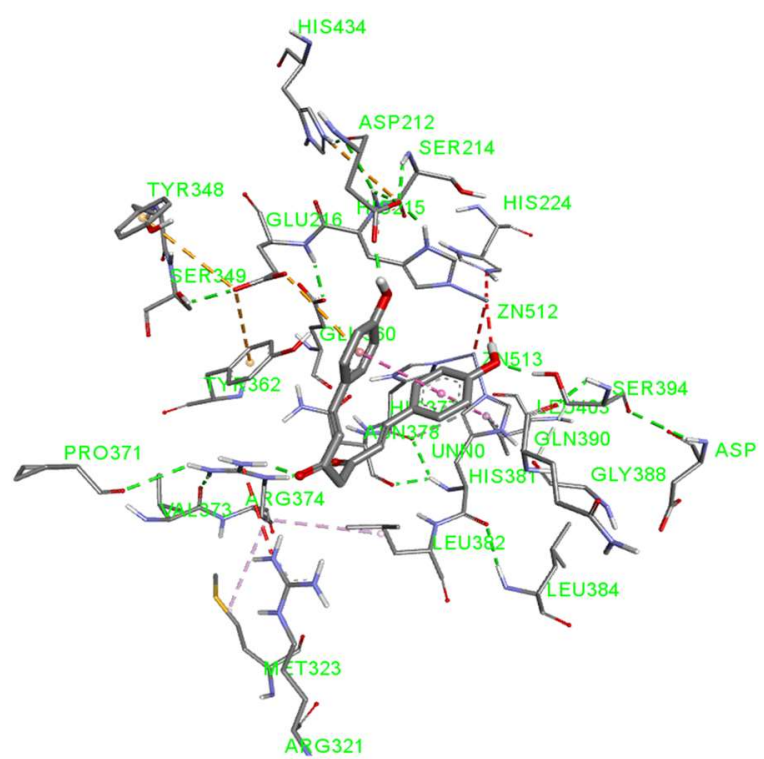

(b)

Fig.-4: The Binding Mode of (a) Turmerone with Tyrosinase; (b) Bisdemethoxycurcumin with TRP-1.

The Hydrogen Bond is Shown as Green Dashed-lines, while the Hydrophobic Interaction is Visualized by the Pink or Red Dashed-lines.

Molecular docking of curcumin, demethoxycurcumin, bisdemethoxycurcumin, and turmerone into the site in which kojic acid was co-crystallized are presented in Table-1. The results indicate that all ligands contained in C. longa could bind to tyrosinase and TRP-1, and interestingly, their binding modes are similar 
to those of kojic acid. Of all ligands, turmerone binds strongly to tyrosinase (Fig.-4a), whereas bisdemethoxycurcumin shows the strongest affinity to TRP-1 (Fig.-4b).

Table-1: The Binding Mode and Affinity of the Ligands in Tyrosinase and TRP-1

\begin{tabular}{|c|c|c|c|}
\hline \multirow[t]{2}{*}{ No. } & \multirow[t]{2}{*}{ Ligand } & \multicolumn{2}{|c|}{$\begin{array}{l}\text { Binding Affinity in term of Docking Score }(\mathrm{kcal} / \mathrm{mol}) \text { and Amino Acid } \\
\text { Residues Involved in the Interaction }\end{array}$} \\
\hline & & Tyrosinase & TRP-1 \\
\hline 1. & Kojic acid & $\begin{array}{l}-2.57 \mathrm{kcal} / \mathrm{mol} \\
\text { Hydrogen bond: } \\
\text { Gly196, Asn205 } \\
\text { Hydrophobic interaction: } \\
\text { Pro201, Arg209 }\end{array}$ & $\begin{array}{l}-4.01 \mathrm{kcal} / \mathrm{mol} \\
\text { Hydrogen bond: } \\
\text { Gly389, Ser394 } \\
\text { Hydrophobic interaction: } \\
\text { None detected }\end{array}$ \\
\hline 2. & Curcumin & $\begin{array}{l}-1.95 \mathrm{kcal} / \mathrm{mol} \\
\text { Hydrogen bond: } \\
\text { Asn205* } \\
\text { Hydrophobic interaction: } \\
\text { Pro201* }\end{array}$ & $\begin{array}{l}-6.49 \mathrm{kcal} / \mathrm{mol} \\
\text { Hydrogen bond: } \\
\text { Glu216, Arg374, His381, Ser394** } \\
\text { Hydrophobic interaction: } \\
\text { Tyr362, Leu382 }\end{array}$ \\
\hline 3. & Demethoxycurcumin & $\begin{array}{l}-2.88 \mathrm{kcal} / \mathrm{mol} \\
\text { Hydrogen bond: } \\
\text { Gly196*, Asn205* } \\
\text { Hydrophobic interaction: } \\
\text { Met61, Met184, Phe197 }\end{array}$ & $\begin{array}{l}-6.86 \mathrm{kcal} / \mathrm{mol} \\
\text { Hydrogen bond: } \\
\text { Glu216, Arg374, His381, Ser394** } \\
\text { Hydrophobic interaction: } \\
\text { Tyr362, Leu382 }\end{array}$ \\
\hline 4. & Bisdemethoxycurcumin & $\begin{array}{l}-3.36 \mathrm{kcal} / \mathrm{mol} \\
\text { Hydrogen bond: } \\
\text { Gly196*, Asn205* } \\
\text { Hydrophobic interaction: } \\
\text { Phe197, Arg209* }\end{array}$ & $\begin{array}{l}-6.92 \mathrm{kcal} / \mathrm{mol} \\
\text { Hydrogen bond: } \\
\text { Asp212, Arg374, Ser394** } \\
\text { Hydrophobic interaction: } \\
\text { Glu216, His381 } \\
\end{array}$ \\
\hline 5. & Turmerone & $\begin{array}{l}-3.96 \mathrm{kcal} / \mathrm{mol} \\
\text { Hydrogen bond: } \\
\text { Asn205* } \\
\text { Hydrophobic interaction: } \\
\text { Met61, Phe197, Pro201*, } \\
\text { His208, Arg209* }\end{array}$ & $\begin{array}{l}-6.48 \mathrm{kcal} / \mathrm{mol} \\
\text { Hydrogen bond: } \\
\text { Arg374 } \\
\text { Hydrophobic interaction: } \\
\text { His } 192 \text {, His } 215 \text {, Tyr362, His } 381 \text {, } \\
\text { Leu382, Phe } 400\end{array}$ \\
\hline
\end{tabular}

* indicates similar interaction with kojic acid in tyrosinase; ** indicates similar interaction with kojic acid in TRP-1

Our results correlate with that of Park and colleagues (2011). It was reported that aromatic-turmerone inhibited the expression of tyrosinase, TRP-1, and TRP-2 in B16F10 cells. In this previous in vitro study, aromatic-turmerone was confirmed to possess stronger anti-melanogenic activity than curcumin. ${ }^{13}$ Moreover, it was reported previously that curcumin of $C$. longa reduced the tyrosinase activity in $\alpha-\mathrm{MSH}-$ stimulated B16F10 cells. ${ }^{14,15}$ Interestingly, bisdemethoxycurcumin isolated from the rhizomes of Alpinia galangal, was reported to exhibit a minor inhibitory activity of cellular tyrosinase and melanin contents. ${ }^{16}$ This study positively corresponds with our in silico study, that bisdemethoxycurcumin's binding affinity with tyrosinase (presented in Table-1), is weaker than that of turmerone.

However, Du and co-workers had reported that curcumin analogs with $o$-diphenols formed a $\pi$ - $\pi$ stacking with His194 and multiple hydrogen bonds with Gly183, Trp184, and Ser206, while curcumin analogs with $m$-diphenols interacted with Ser146, Asn188, Asn191, Ala202, Thr203, and Ser206. ${ }^{17}$

Many plants have been reported for their activity in inhibiting tyrosinase, thus, these plants are potential to be developed as skin-whitening agents. A recent study reported that gossypol contained in the cotton seeds has shown interaction with tyrosinase. ${ }^{18}$ Moreover, wild Torreya grandis seed oil was reported could inhibit tyrosinase activities. ${ }^{19}$

\section{CONCLUSION}

Discovering a novel plant-based skin lightening agent is always challenging. Curcumin and aromaticturmerone were reported could reduce the tyrosinase activity in $\alpha-\mathrm{MSH}$-stimulated B16F10 cells. Our work 
studied the molecular interaction of curcumin, demethoxycurcumin, bisdemethoxycurcumin, and turmerone of Curcuma longa with tyrosinase and TRP-1 study. Of all ligands, turmerone binds strongly to tyrosinase, whereas bisdemethoxycurcumin shows the strongest affinity to TRP-1. Considering this, $C$. longa could be further developed as a plant-based skin whitening-cosmetic.

\section{ACKNOWLEDGEMENT}

The authors thank (1) the Rector of Universitas Padjadjaran for funding the publication fee via the Directorate of Research and Community Service (DRPM) and (2) the Center for Computational Research, Faculty of Pharmacy, Universitas Padjadjaran for granting permission to use the Discovery Studio Program.

\section{REFERENCES}

1. J. M. Gillbro and M. J. Olsson, International Journal of Cosmetic Science, 33(3), 210(2011), https://doi.org/10.1111/j.1468-2494.2010.00616.x

2. K. Muthia, F. R. Alami, N. M. Saptarini and J. Levita, Proceedings of the 3rd International Conference on Computation for Science and Technology, Atlantis Press, 2015.

3. I. F. dos Santos Videira, D. F. L. Moura and S. Magina, Anais Brasileiros de Dermatolologia, 88(1), 76(2013), https://dx.doi.org/10.1590\%2FS0365-05962013000100009

4. J. H. Yoon, J. S. Shim, Y. Cho, N. I. Baek, C. W. Lee, H. S. Kim and J. K. Hwang, Biological \& Pharmaceutical Bulletin, 30(11), 2141(2007), https://doi.org/10.1248/bpb.30.2141

5. I. Kubo, I. Kinst-Hori, S. K. Chaudhuri, Y. Kubo, Y. Sánchez and T. Ogura, Bioorganic \& Medicinal Chemistry, 8(7), 1749(2000), https://doi.org/10.1016/s0968-0896(00)00102-4

6. H. Matsuda, S. Nakashima, Y. Oda, S. Nakamura and M. Yoshikawa, Bioorganic \& Medicinal Chemistry, 16, 6048(2009), DOI: https://doi.org/10.1016/j.bmc.2009.06.057

7. C. X. Tu, M. Lin, S. S. Lu, X. Y. Qi, R. X. Zhang and Y. Y. Zhang, Phytotherapy Research, 26(2), 174(2012), https://doi.org/10.1002/ptr.3517

8. M. Sendovski, M. Kanteev, V. S. Ben-Yosef, N. Adir and A. Fishman, Journal of Molecular Biology, 405(1), 227(2010), https://doi.org/10.1016/j.jmb.2010.10.048

9. X. Lai, H. J. Wichers, M. Soler-Lopez and B. W. Dijkstra, Angewandte Chemie International Ed in English, 56(33), 9812(2017), https://doi.org/10.1002/anie.201704616

10. S. Megantara, J. Levita, S. Ibrahim and B. P. Nguyen, Rasayan Journal of Chemistry, 14(1), 241(2021), http://dx.doi.org/10.31788/RJC.2021.1416070

11. A. Asadzadeh, H. Sirous, M. Pourfarzam, P. Yaghmaei and F. Afshin, Iranian Journal of Basic Medical Sciences, 19(2), 132(2016).

12. M. Saeedi, M. Eslamifar and K. Khezri, Biomedicine \& Pharmacotherapy, 110, 582(2019), https://doi.org/10.1016/j.biopha.2018.12.006

13. S. Y. Park, M. L. Jin, Y. H. Kim, Y. Kim and S. J. Lee, Archives of Dermatological Research, 303(10), 737(2011), https://doi.org/10.1007/s00403-011-1155-7

14. J. H. Lee, J. Y. Jang, C. Park, B. W. Kim, Y. H. Choi and B. T. Choi, International Journal of Molecular Medicine, 26(1), 101(2010), https://doi.org/10.3892/ijmm_00000440

15. J. A. Kim, J. K. Son, H. W. Chang, Y. Jahng, Y. Kim, M. K. Na and S. H. Lee, Natural Product Communications, 3(10), 1655(2008).

16. V. Ragavan, A. Ramesh and R. Narayanaswamy, Rasayan Journal of Chemistry, 13(1), 469(2020), http://dx.doi.org/10.31788/RJC.2020.1315541

17. Z. Y. Du, Y. F. Jiang, Z. K. Tang, R. Q. Mo, G. H. Xue, Y. J. Lu, X. Zheng, C. Z. Dong and K. Zhang, Bioscience, Biotechnology, and Biochemistry, 75(12), 2351(2011), http://dx.doi.org/10.1271/bbb.110547

18. C. Y. Lo, P. L. Liu, L. C. Lin, Y. T. Chen, Y. C. Hseu, Z. H. Wen and H. M. Wang, Scientific World Journal, 2013, 186505(2013), http://dx.doi.org/10.1155/2013/186505

19. H. X. Cui, F. F. Duan, S. S. Jia, F. R. Cheng and Ke Yuan, Biomed Research International, 2018, Article ID 5314320 (2018), https://doi.org/10.1155/2018/5314320

[RJC-6418/2021] 